\title{
ПСИХОЛОГИЧЕСКАЯ ТРАНСФОРМАЦИЯ ЛИЧНОСТИ В ЭПОХУ ГЛОБАЛЬНЫХ ПЕРЕМЕН И МЕТАФОРИЧЕСКОЕ ПРОСТРАНСТВО СКАЗКИ
}

Мурадян Е.Б. (Ереванский государственный университет, Ереван, Армения)

yelena.muradyan@ysu.am

Utinlujugvimi mर्u.' 07.08.2019

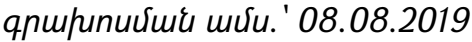

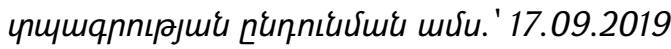

В статье процесс глобализации рассматривается с точки зрения его воздействия на человека. Обращается внимание на некоторые изменения в “категориальной системе психологии" в плане содержательной трансформации психологических категорий, что также связывается с влиянием глобализации на человека. Рассматриваются характерные особенности эпохи глобальных перемен в широком диапозоне. Особое внимание уделяется пониманию “психологической трансформации личности” в связи с процессом глобализации. Предпринимается попытка использовать метафорическое пространство сказки в качестве средства и способа объяснения процесса “трансформации личности” под воздействием глобализации.

Ключевые слова: глобализачия, психологическая трансформачия личности, метафора, метафорическое пространство сказки

Понимание того, что эпоха глобальных перемен оказывает на человека воздействие, приводящее к психологической трансформации его личности, затрагивая при этом практически все уровни проявления психического, на сегодняшний принимается научным сообществом как данность. Если обратиться к “категориальной системе психологии" [11], то становится очевидным, что наиболее значимые понятия психологии, составляющие кластеры категорий психосферы, претерпевают содержательную трансформацию на уровне теоретического осмысления, что отражает реальные изменения качественного порядка в пространстве психосфреры. В результате изменений, происходящих в эпоху “текучей реальности”, для которой характерны непредсказуемость, неопределенность, разнообразие, сложность ...[1], также меняется “приоритетный смысл” в содержательном позиционировании основных понятий в психологии, которые приобретают более "современное” звучание, но менее привлекательную "окраску" с морально-нравственной и духовной позиций. Так например, метапсихологическую категорию личность уже будет правильнее рассматривать как “изменяющуюся личность в изменяющемся мире”, причем не всегда ясно, изменяющуюся в плане развития, личностного роста или в плане “легкости” смены жизненных принципов, ценностей, идеалов в соответствие с современными новообразующимися стандартами жизненных норм, 
например, “толерантность к злу и смирение перед ним” [13, с.28]. Отмечается, что эпоха глобальных перемен не оставляет человеку времени на осмысление бытия и происходящих в нем событий, не способствует фрормированию у него системы общечеловеческих ценностей, однако является “благодатной почвой” для развития утилитарного, потребительского отношения к субъектам и объектам окружающей его действительности [12].

Возникает вопрос: “Почему так происходит?" Чтобы разобраться в этом вопросе, определимся с тем, что понимается под “эпохой глобальных перемен”. Наиболее универсальное понимание процесса “глобализации” сводится к преобразованию мира в единое социально-экономическое пространство, в которое вплетены различные культурно-идеологические “конструкции” [10]. Эпохальное значение глобализации объясняется тем, что в связи с этим процессом происходят масштабные изменения во всех сфрерах жизнедеятельности человеческих сообществ, в результате чего меняется экономическая, политическая, социальная, духовная составляющие современной эпохи. Следует отметить, что в отношении глобализации, в оценочном контексте, высказываются диаметрально-противоположные взгляды: от отождествления этого процесса с экономическим, технологическим и социальным прогрессом, с естественным, объективным ходом развития “современной мирохозяйственной системы”, - до представления этого процесса как насильственной унификации мира под воздействием американизма [10]. Не впадая в крайности, следует подчеркнуть, что характерными чертами глобализации являются взаимосвязанность и взаимозависимость, “единение человечества в целостном мире, взаимодействие внутри такой целостности разнородных и разнообразных национальных, религиозных, государственно-политических компонентов” [9, с. 137-138]. Однако приводимые описания глобализации никак не указывают на какие-либо аспекты деструктивного воздействия этого процесса на развитие общества как в масштабе государств, так и в масштабе мира. Однако механизм глобализации, способствуя прогрессивному развитию человеческого сообщества в экономическом, технологическом плане, несет в себе также и разрушительный потенциал: “среди составляющих той непомерной социальной цены, которую пришлось заплатить за радикальные экономические реформы в России - пренебрежение нравственно-психологическим миром человека" [3, с.588]. В условиях глобализирующегося мира нивелируются ценности, которые на протяжении веков считались таковыми, сохранялись и передавались от поколения к поколению, а на смену иллюзорным представлениям о гуманизме и демократии приходит “реальная” реальность как “выражение жажды власти и жестокой технической решимости” [6, с. 490]. Эти примеры лишь частично объясняют возникновение деструктивных тенденций в развитии общества в эпоху глобальных перемен, т.к. могут рассматриваться, с одной стороны, в качестве причин этих тенденций, с другой, - в качестве самих деструктивных тенденций (например, “пренебрежение нравственно-психологическим миром 
человека"). Однако для более глубокого анализа происходящего необходимо выявление тех социально-психологических механизмов, которые порождая ряд причинно-следственных событий, приводят к возникновению этих деструктивных тенденций в эпоху глобальных перемен.

Bce сказанное подтверждает неоднозначность воздействий масштабных перемен в процессе глобализации на различные человеческие сообщества, вовлеченные В этот процесс, указывая на противоречия и конфликты, проявляющиеся во всех сфрерах жизнедеятельности человека. Возникает острая необходимость понимания того, как влияет “изменяющийся мир” на человека, на духовно-нравственный потенциал личности?

Обращаясь к ряду исследований, становится очевидным, что глобализация, технологически усложняющееся развитие общества приводят к трансформации идентичности человека, к редуцированию личности в “двоичной цифровой логике трансгуманизма”, его “инвалидизации” и “киборгизации” [5, с. 113-114]. "Побочным" продуктом глобализации становится трансформация человеческих ценностей, что приводит к проявлениям на личностном уровне парадоксальности, нестабильности, “контекстуальных проявлений ее (личности) субъектности и субъективности” [4, с.16]. Также отмечается, что глобализация, способствуя индивидуализации, приводит к росту национализма, в то же время обеспечивает многообразие индивидуальных стилей социализации [4]. Особый интерес представляет исследование, посвященное проблеме эволюции идентичности современного студента. Было показано, что за последние 17-18 лет наблюдается резкое снижение показателей выраженности гражданской, семейной, дружественно-коммуникативной сфер идентичности современной молодежи по сравнению с идентичностью молодежи прошлых лет. В то же время, вырисовывается новый образ современного студента, для которого характерны: склонность к индивидуализму, тяготение к интернетинформационному сообществу, проявление деятельностной активности, склонность к самосовершенствованию, стремление к дальнейшему обучению [8].

В связи с происходящими трансформационными процессами на уровне личности, на уровне ценностей и т.д., было предложено обращаться к “трансдисциплинарному исследованию современного изменяющегося человека в современном изменяющемся мире” [4, с.17]. На наш взгляд, одним из возможных способов объяснения происходящего может стать “метафорический подход”, а в качестве средства может использоваться - “сказочная метафора”.

На возможность обращения к метафоре при изучении различных аспектов “человеческого" в человеке уже указывалось некоторыми исследователями, метафора в своей сущности рассматривалась как лежащая в основе возникновения языка и мышления, а в качестве ее функциональной особенности рассматривалась уникальность и нестандартность представления и осмысленияая объективного [7]. 
Как отмечает И.В. Вачков, практика использования метафоры для объяснения и понимания мира, социальной действительности существует давно, и, например, современный этап развития общества наиболее ярко характеризуется метафорой мира как паутины, а люди, оказавшись в ней, связаны друг с другом сетями Интернета [2]. Подобная метафоризация подводит к осмыслению позиции человека в современном мире: оказались ли люди в этой паутине по своей воле или запутались в ней, были “пойманы”, тогда кем, или какие социальные процессы подвели человечество к этой форме бытия и как это влияет на человека, на его будущее в глобальном масштабе? Подобная постановка вопросов способствует лучшему пониманию ситуации, а “метафорический” стиль осмысления позволяет в конкретном увидеть множественность и неопределенность, многоаспектность и многозначность.

Вообще, идея использования метафоры в научном дискурсе вызывает споры, но современные исследования указывают на эффективность такого подхода [7]. В связи со сказанным возможно осмысление процесса глобализации с использованием метафорического пространства сказки, сказки как одной из наиболее ранней, наиболее понятной и доступной формы литературного жанра. В народных и авторских сказках, проверенных временем, особенно в волшебных сказках, можно заметить предвосхищающие свое время описания тех социально-психологических, технологических тенденций, которые характерны для современности. Человека как бы подготавливали к сегодняшнему дню, к эпохе модернизации, трансформации, виртуализации, глобальных перемен, обеспечивая при этом осознание позитивного исхода, характерного для русских народных сказок. Так например, появлению современных технических средств передвижения, новых технологий в сфере коммуникаций предшествовали их "сказочные" прототипы: ковер-самолет, сапогискороходы, котелок с “зельем”, зеркальце, в которых можно увидеть человека, находящегося, например, в другой стране или просто за пределами зрительной доступности и многое другое. Весьма примечательно, что в сказках встречается описание преображения, превращения, когда купание в кипящем молоке приводит к омоложению и “умственному просветлению", что в современной реальности соответствует повальному увлечению пластической хирургией (что, чаще всего, обусловлено искажениями в мотивационно-ценностной сфере личности), когда изменяются формы, но сохраняется трансформированное "содержание" собственной экзистенции. Анализ сказок в подобном ключе, но на уровне детального научного осмысления сказочного нарратива с использованием метафоры, возможно, позволит выявить некоторые нюансы механизмов преобразования современного общества. А содержащиеся в сказках посылы о жизненных ценностях, о личностных смыслах, о морально-нравственных ориентирах, выражаемые с помощью метафор, возможно, позволят осознать, что необходимо предпринять, чтобы “психологическая трансформация личности” не рассматривалась бы в 
широком диапозоне этического релятивизма, а ассоциировалась бы с четкими представлениями о ценности человеческой жизни.

\section{Литература}

1. Асмолов А.Г. Психология современности: вызовы неопределенности, сложности и разнообразия. Психологические исследования, 2015, Т. 8, N40, C.1. URL:http://psystudy.ru (дата обращения: 25.10.2018)

2. Вачков И.В. Метафора как средство психологической работы в тренинге с педагогами // Вестник Балтийского федерального университета им. И. Канта, 2015, Вып.5, С. 68-74.

3. Гринберг Р.С. Пятнадцать лет рыночной экономики в России // Вестник PAH, 2007, T.77, N7, C. 584-592.

4. Гусельцева М.С. Методология XXI века: субъект и личность в трансформирующемся обществе // Личность в эпоху перемен: mobilis in mobile: Материалы международной научно-практической конференции 17-18 декабря 2018 / Под ред. Е.Ю. Патяевой, Е.И. Шлягиной. - М.: Смысл, 2018. - 448с.

5. Емелин В.А. Технологический радикализм: обратная сторона "цифрового" рая // Личность в эпоху перемен: mobilis in mobile: Материалы международной научно-практической конференции 17-18 декабря 2018 / Под ред. Е.Ю. Патяевой, Е.И. Шлягиной. - М.: Смысл, 2018. - 448с.

6. Ерасов Б.С. Сравнительное изучение цивилизаций.- М., М.: Аспект-Пресс, 1998. 536 с.

7. Козлова Н.Ю. Метафора как способ трансцендентальной рефрлексии познающего Я // Дис. На соискание уч.ст.канд.фрилос.наук., Московский педагогический государственный университет, М.-2016, 163с.

8. Кондаурова О.П. Эволюция идентичности современного студента // Личность в эпоху перемен: mobilis in mobile: Материалы международной научно-практической конференции 17-18 декабря 2018 / Под ред. Е.Ю. Патяевой, Е.И. Шлягиной. - М.: Смысл, 2018. - 448с.

9. Мнацаканян М.О. Глобализация и национальное государство: три мифа // Социс.- 2004, N5, с.137-142.

10. Осинский И.И. К вопросу о сущности современных глобальных проблем // Вестник Бурятского Государственного Университета. Философия.- 2017.Вып.5, с. 29-35.

11. Петровский А.В., Ярошевский М.Г. Теоретическая психология.- М.: Издательский центр “Академия”, 2001. 496 с.

12. Ручкина Г.Ф. Общество и личность в эпоху перемен: Российская специфика // Сборник материалов Всероссийской научной конференцииМосква: РИПО, 2007, с.212-219. Электронный ресурс (URL: http://www.civisbook.ru/files/File/Ruchkina.pd). 
13. Юревич А.В. Нравственная деградация как угроза национальной безопасности России // Проблема психологической безопасности / Отв.ред. А.Л. Журавлев, Н.В. Тарабрина.- М.: Изд-во “Институт психологии РАН", 2012. 440 c., c.25-46.

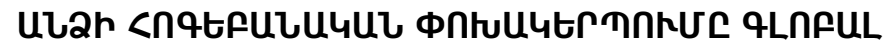

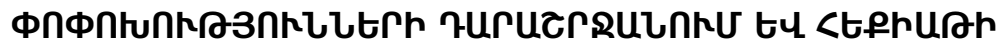 Фntuuftruuul surudnhaзnklc}

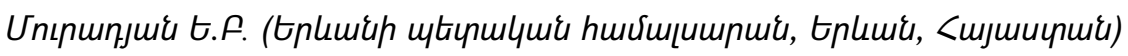

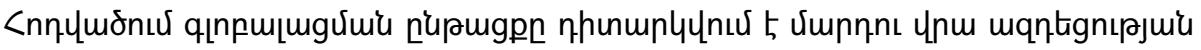

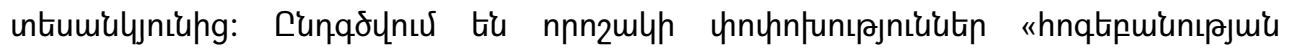

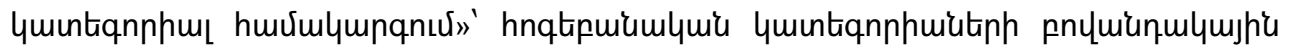

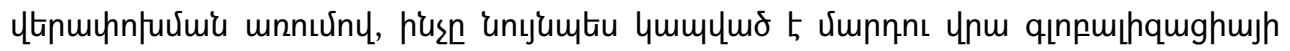

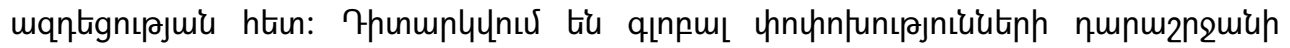

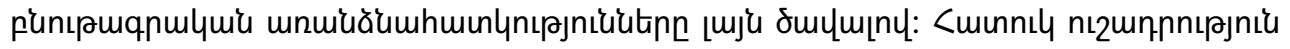

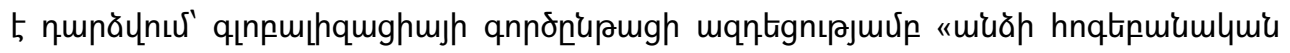

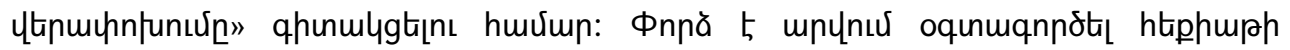

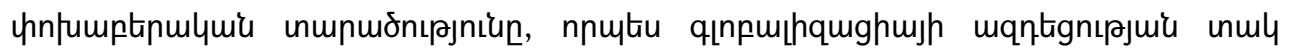

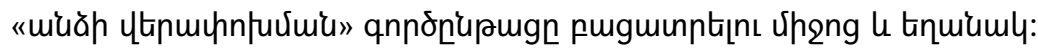

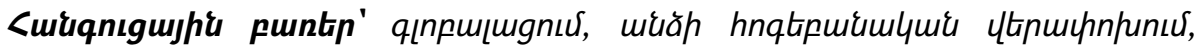

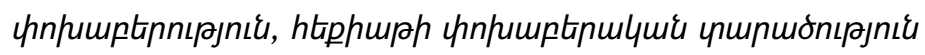

\section{PSYCHOLOGICAL TRANSFORMATION OF PERSONALITY IN THE ERA OF GLOBAL CHANGE AND FAIRY -TALE'S ALLEGORICAL SPACE}

Muradyan Ye.B. (Yerevan State University, Yerevan, Armenia)

The article considers the process of globalization from the point of view of its influence on a person. Are emphasized some changes in "categorical system of psychology", taking into consideration substantial transformation of psychological categories, which is also explained by the influence of globalization on a person. Global change era's characteristic features in the wide range are as well considered. Particular attention is being focused on "psychological transformation of personality" in connection with the processes of globalization. Fairy-tale's allegorical space, as mean and method, is attempted to be practiced in order to explain "personality transformations" under the influence of globalization.

Keywords: globalization, psychological transformation of personality, metaphore, fairy tale's allegorical space. 